\title{
Web 2.0-Based Academician Profile Information System
}

\author{
${ }^{1 *}$ Lee Beng Yong, ${ }^{2}$ Rosita Suhaimi, ${ }^{3}$ Iris Syawe Seh Ling, ${ }^{l}$ Robert John Jingut, ${ }^{2}$ Hawa Nahar \\ ${ }^{1}$ Faculty of Computer \& Mathematical Sciences, ${ }^{2}$ Faculty of Business Management, ${ }^{3}$ Faculty of \\ Applied Sciences, Universiti Teknologi MARA, Kota Samarahan, Sarawak, Malaysia.

\section{*bylee@sarawak.uitm.edu.my}

\begin{abstract}
The Publication, Training, and Research Administration System (PuTRAS) is an information system developed through in-house development for keeping academician profiles for Universiti Teknologi MARA, Sarawak Campus in Web 2.0 environment. This paper addresses the experiences in the process of acquiring requirement, creating the design through rapid prototyping, implementing the solution, and the evaluation and testing of that solution in read/write Web 2.0 environment. A unique feature in PuTRAS is to allow staff to provide and monitor their own records, which later are validated by authorized users of the system. This feature of PuTRAS has significantly simplified the conventional record keeping process and ensured that important records of the staff are authentic. A simple questionnaire was used to collect feedback from various users and the analysis shows a very positive result on user satisfaction towards the usage of the system. Lastly, this paper will share some pre-post experience of PuTRAS implementation. Awards won by this project are also listed at the end of this paper.
\end{abstract}

Keywords: Architectures for educational technology system; Human-computer interface

\section{Introduction}

Keeping publication and research records of thousands of academicians in Universiti Teknologi MARA (UiTM) is a difficult task especially when these academicians are located in various branch campuses around Malaysia and new records has to be updated promptly. Therefore an initiative has been taken to implement an information system to keep records on publication and research and training records of the staff in UiTM, Sarawak campus. The system, named as Publication, Training and Research Administration System (PuTRA) has been developed since July 2004 and was officially launched in April 2005.

During the beginning of the development, various system architectures were studied and considered. Among the system architecture studied were Stand-alone system, Client-server based system and Web 2.0-based system [6]. Web 2.0 sites such as Wikipedia, YouTube, and Facebook provides a means for users to share personal information and web contents. These features allow users to modify Web site content and empower users to actively contribute to the content of the Web [2]. According to Lenhart, Horrigan \& Fallows [4], in 2003, 44\% of adult Internet users had experience creating at least one content on the Web[2].

By taking into the consideration of the fact of popularity of Web 2.0 and the requirement of the system that will have to handle heavy usage from users, the author and the development committee have decided to adopt Web 2.0 as the platform to implement the system.

\section{Motivation}

Before PuTRAS was implemented, the practice used in the university to collect publication, training and research records was to distribute and collect printed forms from staff from time to time. After the forms were collected, the records were entered into spreadsheet and word processing software. The calculation and the analysis of the records were done manually. With this conventional practice, various problems have occurred. Among the problems are:

- Time consuming to generate reports and analysis,

- Required a lot of human efforts,

- Incomplete and inaccurate data,

- Difficulty in planning for staff training and development,

- No sharing of information regarding academic staff's research and publication. 


\section{System Architecture}

The Web 2.0-based PuTRAS was developed in Three-tier architecture. The three-tier architecture promotes a clean separation between the system presentation layer and the system data management layer because all communication is routed through the business layer of the system. In PuTRAS, the three-tier are referring to a Front End tier, the content rendered by web browsers, a middle dynamic content processing and generation tier i.e. PHP 5.0 and a back-end database tier that manages and provides access to the data, i.e. MySQL 5.1 server.

\subsection{Front-end tier}

Presentations of the system are web pages rendered by web browser based on HTML 4.0 page source responded by the system web server. The layout of every web page is standardized using Cascading Style Sheet and interactions between users and web pages are controlled using JavaScript to validate input from the users.

Some of the reports from the system are presented in chart format rendered in Portable Network Graphics (PNG) format. These charts are then included into the web pages through HTML.

In the university, every academic staff is given a computer with pre-installed Internet Explorer 7.0. However there are also computers which have upgraded their own software to Internet Explorer 8 or Mozilla Firefox 3 or above.

\subsection{Middle dynamic content processing and generation tier}

During the initial stage of the development, business logics that control the policies of the system were coded using Visual Basic Script in Active Server Page (ASP). This working prototype became operational after 2 months of development. However, since ASP is only supported by Microsoft Internet Information Server (IIS) and has a limitation to support only maximum 10 concurrent sessions in a non-server Microsoft operating system, the author then decided to migrate into PHP5 technologies where it is supported by more web server other than IIS such as Apache, AOLServer, Roxen and THTTPD. Alternatively, it can also run as a Common Gateway Interface (CGI) module.

As a scripting language to define the business logic in the system, PHP5 also has the advantages of being able to run identically on most UNIXs, Windows (95/98/NT/2000) and Macs. Besides, According to PHP manual [1], PHP also has lots of database interfaces to support many existing popular database.

Being an open source scripting language, PHP is not only free but it has also encouraged the public to write thousands of free programming libraries for sharing. PuTRAS has used library from LibChart [7] to generate charts in the reports in the system.

\subsection{Database management tier}

Initially, Microsoft Access 2000 was used as the backend database management system for PuTRAS because of its simplicity and ability to work well with ASP. However, the performance of the system dropped significantly when the number of records increased. This scenario has also been encountered by Riedling \& Selberherr [5] when they were developing their web-based publication database for performance evaluation and research documentation.

To improve the performance of response time, MySQL 5.1 was selected to replace the MS Access 2000 because MySQL 5.1 has better indexing ability. Besides, MySQL 5.1 can support extra features which do not exist in MS Access 2000 such as Trigger and Stored Procedure that make MySQL 5.1 a better backend data tier for the system. 


\section{Rapid Application Development In System Design}

Rapid Application Development [4] method was applied in acquiring the requirement and creating the design in this Web 2.0 based academician profile information system. During the beginning stage of the development, through the review findings of the development committee, there was no available off-the-shelf system that could serve a similar purpose. Therefore neither the users nor the programmer know what to expect from the system at that time. To shorten the time of creating the design and development of the system the author has chosen to use Rapid prototyping to create the system design while developing a system that would guarantee the users satisfaction [3].

Rapid prototyping is an iterative process that involves quick development of a prototype that has limited operational features desired in the final product. Then, through a series of testing and communication with users and revision of the prototype until an acceptable version is created. Rapid prototyping also promote communication between programmers and users as agreed by Jones \& Ritchey [3], having said "the prototype encourages communication between everyone concerned with the effort".

\subsection{System Data Flow And Features}

Figure 1 below shows the data flow of the system PuTRAS. As a Web 2.0 based system, PuTRAS is designed to allow academic staff to create their own profiles records in the system so that the other users including the public can view their profiles through the university's web site.

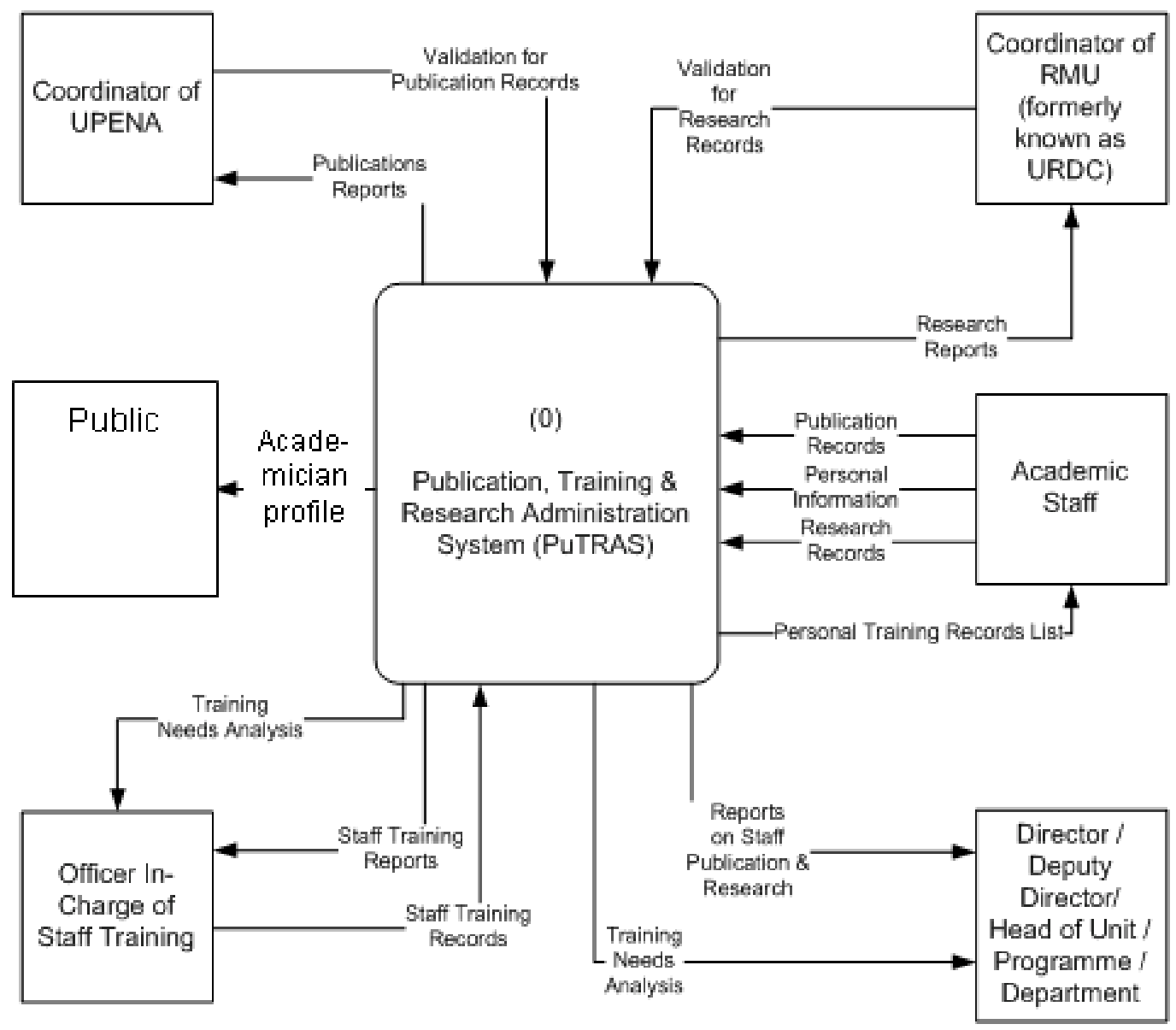

Figure 1: Data Flow Diagram of PuTRAS 
As illustrated in Figure 1, academic profile that can be created by academic staff includes publication records, research records and personal information. Personal information consists of data such as academic qualification, web and email addresses and contact numbers.

Having in mind that not all data provided by users are accurate in all cases, and in some cases, the quality of data might not be realistic. Therefore, it is important to implement some mechanism in the system to validate the data entered.

Two validation modules were created in the system, namely for the purpose of validating contents created by users. The first module was to validate publication records created in the system. The coordinator of University Publication Unit (UPENA) acts as a moderator for records created and decides on the authenticity of each record based on heuristic or hardcopy evidences of the publication. The coordinator of UPENA also decides on either the content should be displayed in the university web site or not. In most cases, publication in books, refereed journal and conference proceedings will be allowed to be visible in university web site while articles in newsletter and newspaper will be hidden from public.

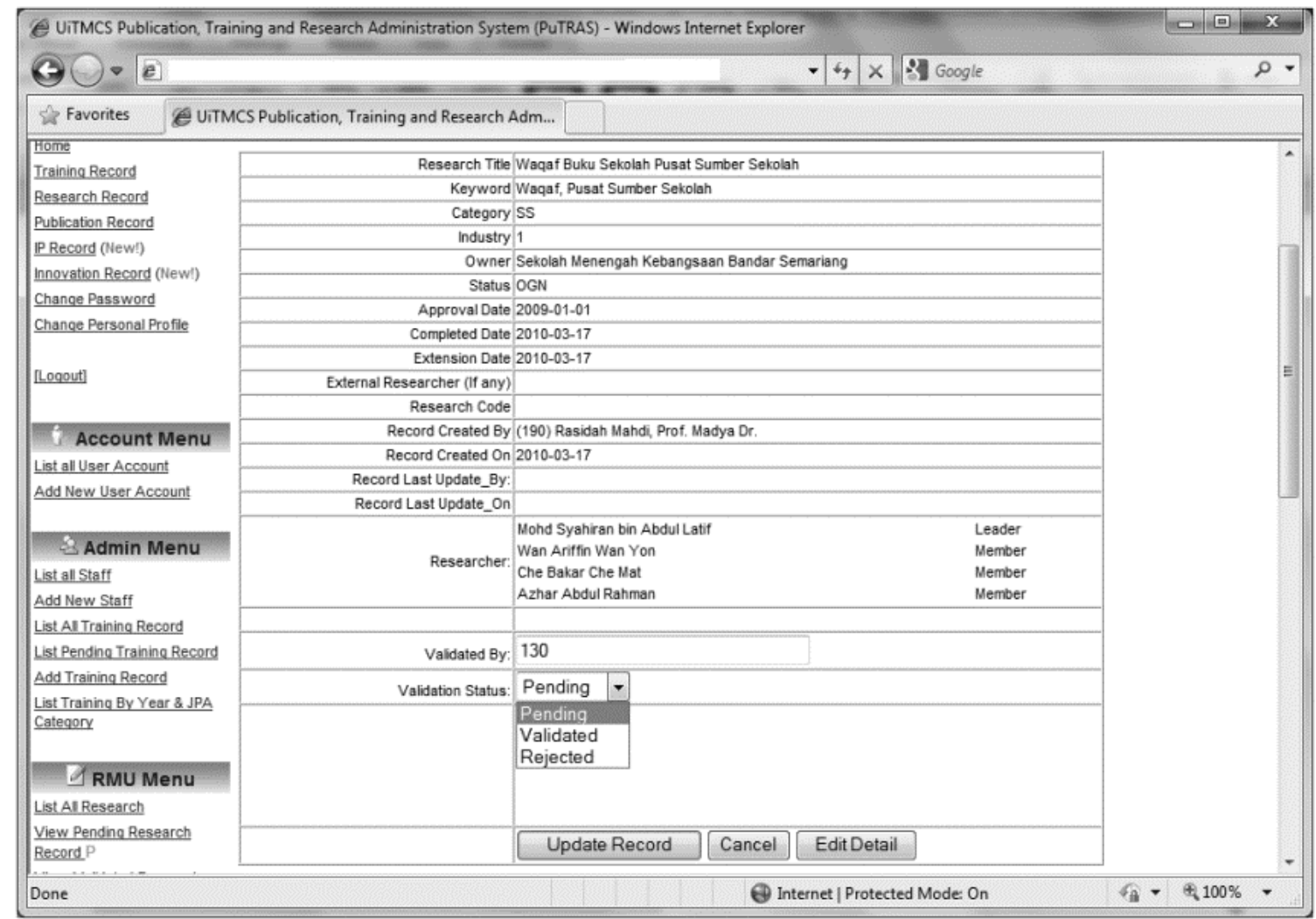

Figure 2: Research record validation module user interface in PuTRAS

The second validation module in the system is to validate the research records created by users. The coordinator of Research Management Unit (RMU) uses the system to check the validity of the contents created as shown in Figure 2. Only validated research record will appear under the academic staff profiles web page. The coordinator of RMU also frequently use records created to monitor the progress of researches conducted by academic staff.

As a Web 2.0-based system, the success of PuTRAS depends on a broad user communities' motivation to make and edit contributions. Like many other Web 2.0 sites, PuTRAS promotes the contribution of contents by allowing the public to view the moderated contents in various formats. Among the interesting output created in the website by utilizing the records entered by user are the graph reports (Figure 3) for the management and authorized users of the system and the electronic directory of academic staff as shown in Figure 4. 


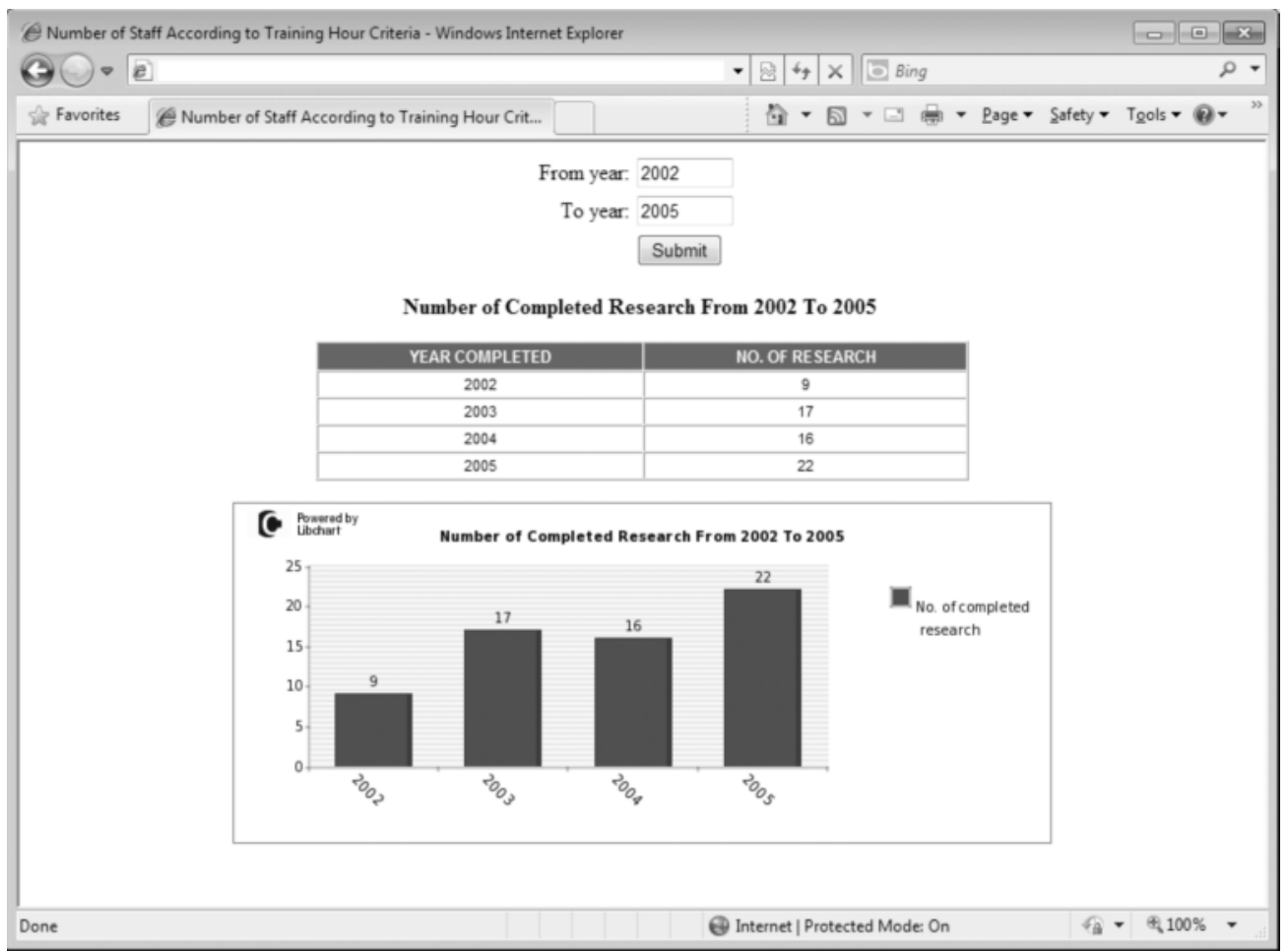

Figure 3: Data in PuTRAS is used to dissemination information in graph format

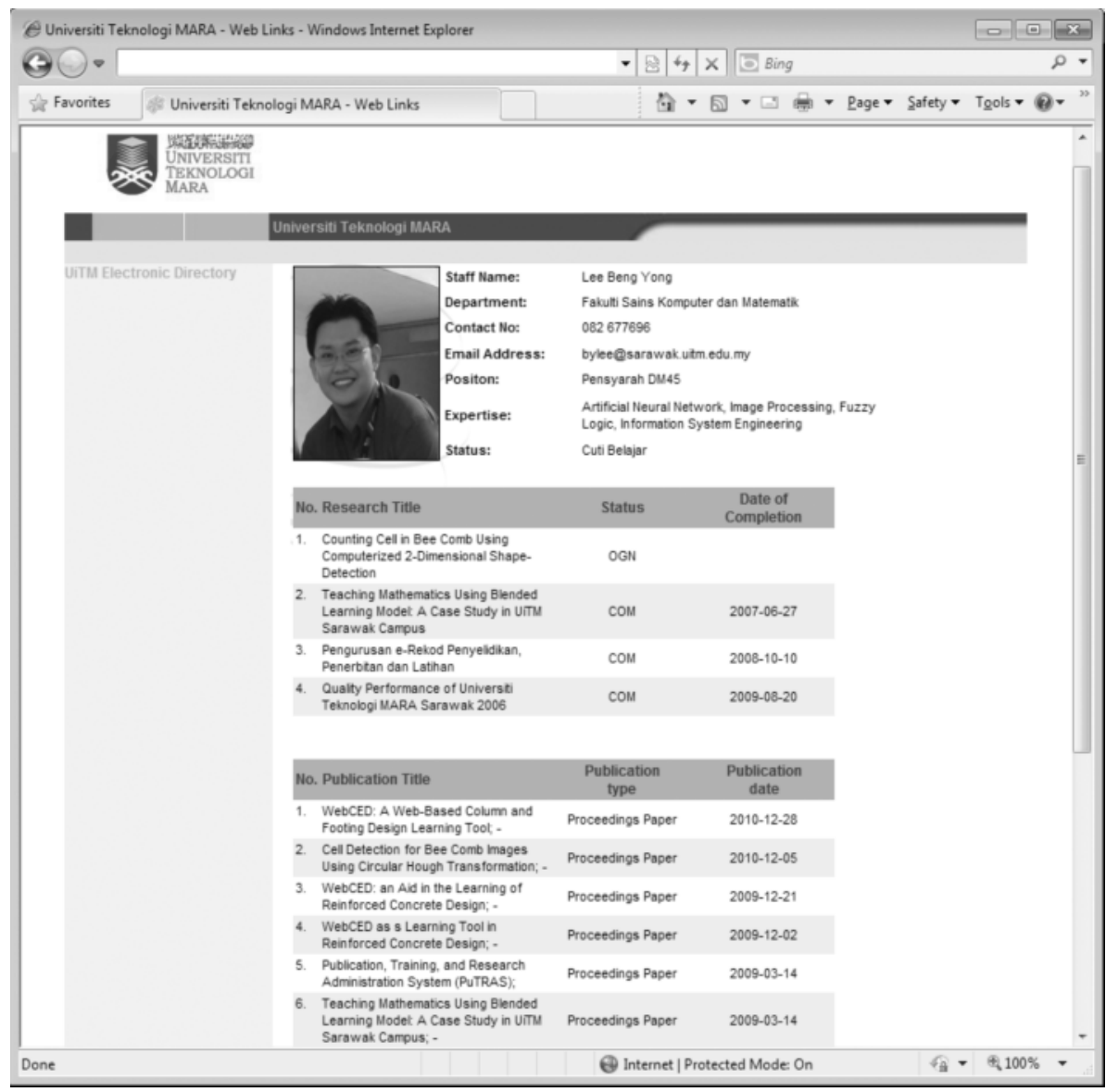

Figure 4: Electronic directory of academic staff in UiTM, Sarawak campus created by utilizing Web 
Another supported format output of the system is Microsoft Excel 2000. Users could use the system to download authenticated contents as an Excel workbook and customized the data into any format that is useful to the users.

\section{Effectiveness of PuTRAS}

A series of interviews has been conducted with the users of the system after the PuTRAS was implemented for the first six months. The objective of the interviews conducted was to find out the differences of time and cost consumption before the PuTRAS was implemented and after using PuTRAS. The differences are clearly compared in Table 1.

Table 1: $\quad$ Comparison of time needed to perform various task before and after the implementation of PuTRAS

\begin{tabular}{|c|c|c|c|}
\hline \multicolumn{2}{|c|}{ Before PuTRAS } & \multicolumn{2}{|c|}{ After PuTRAS } \\
\hline Task & Time Needed & Task & Time Needed \\
\hline $\begin{array}{l}\text { Print Forms + Distribute } \\
\text { Forms + Filling Forms + } \\
\text { Submit Forms }\end{array}$ & 1 week & $\begin{array}{l}\text { Lecturers enter their own } \\
\text { records into PuTRAS }\end{array}$ & $\begin{array}{l}5-10 \text { minutes per } \\
\text { record }\end{array}$ \\
\hline $\begin{array}{l}\text { Enter data into spreadsheet } \\
\text { program }\end{array}$ & 1 month & $\begin{array}{l}\text { Data is automatically saved in } \\
\text { database }\end{array}$ & 0 minute \\
\hline $\begin{array}{l}\text { Manually produce periodical } \\
\text { report }\end{array}$ & 5 days & $\begin{array}{l}\text { PuTRAS produce periodical } \\
\text { reports }\end{array}$ & 1 minute \\
\hline $\begin{array}{l}\text { Manually analyse stored } \\
\text { records }\end{array}$ & 10 days & $\begin{array}{l}\text { PuTRAS analyse stored } \\
\text { records }\end{array}$ & 1 - 2 days \\
\hline
\end{tabular}

\subsection{Users' Acceptance}

A survey was conducted to sample users' feedback toward the usability of PuTRAS. Two hundred (200) copies of questionnaires were distributed to random users, and 30 sets of completed questionnaires were returned. Figures 5, Figures 6, Figures 7, Figures 8 and Figures 9 show the satisfaction level of users towards the Overall organization of the website, User friendliness (button, text), Usefulness (in terms of keeping \& retrieving), Easy to understand, Easy to navigate and Attractiveness respectively.

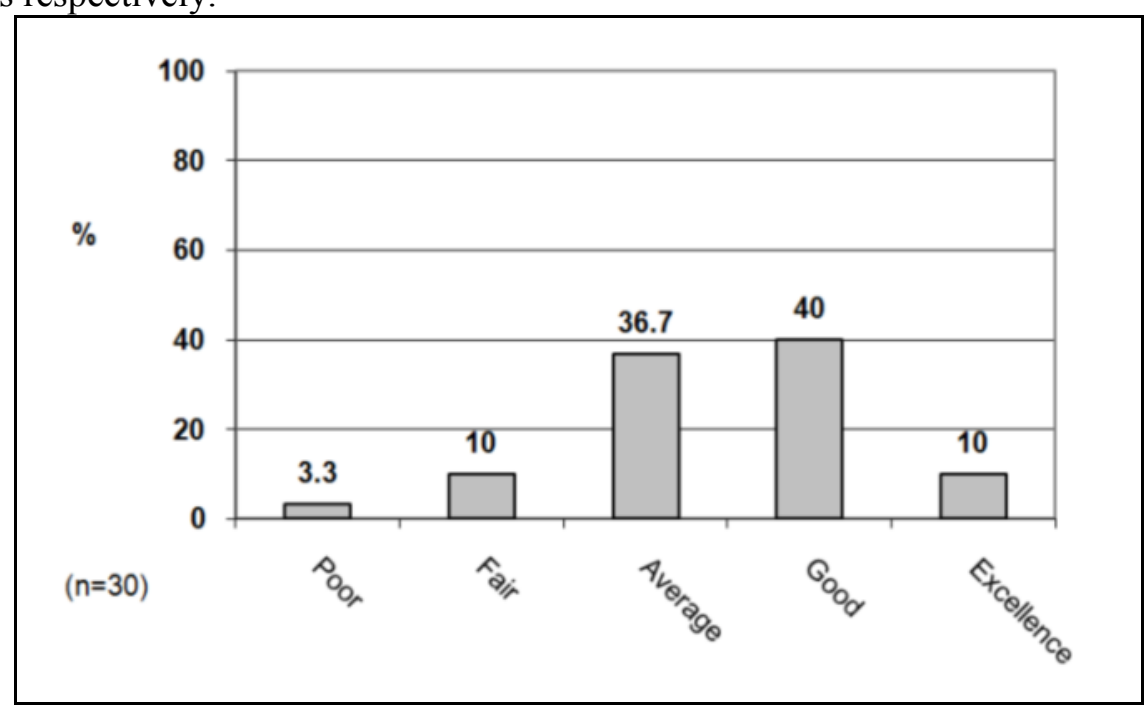

Figure 5: User feedback on satisfaction towards system user friendliness 


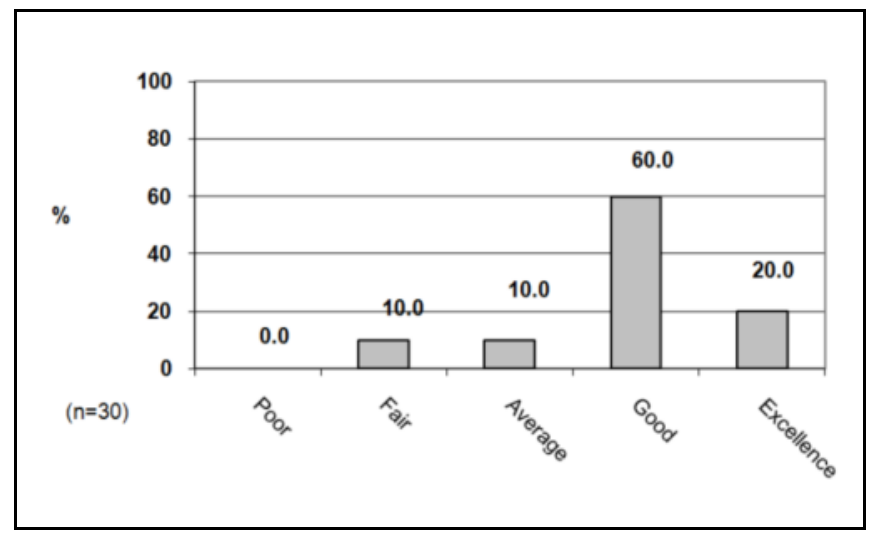

Figure 6: User feedback on satisfaction towards system usefulness

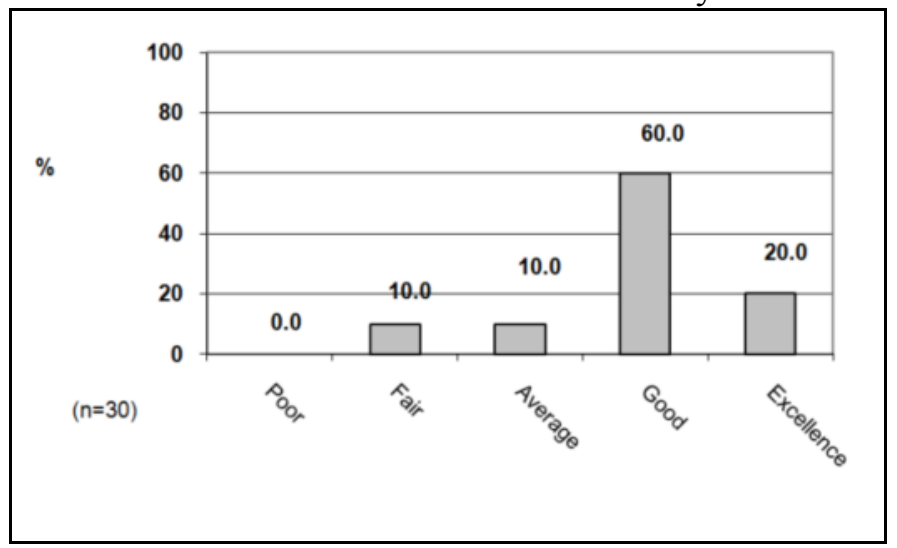

Figure 7: User feedback on satisfaction towards easy to understand

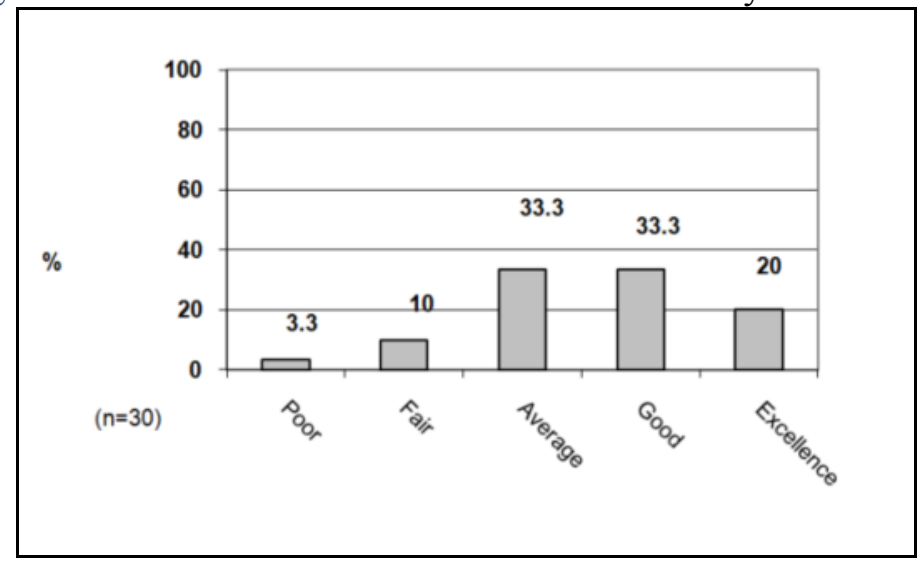

Figure 8: User feedback on satisfaction towards easy to navigate

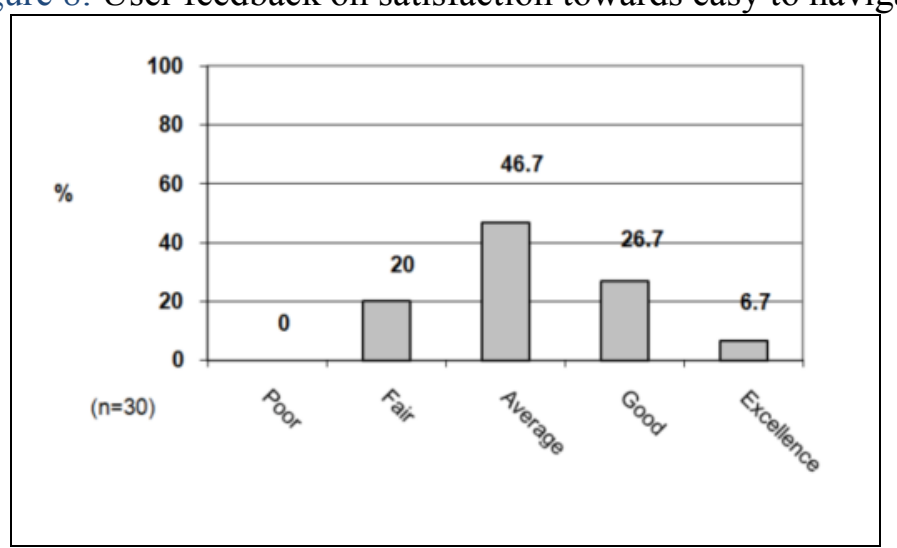

Figure 9: User feedback on satisfaction towards attractiveness 
Overall, users found that PuTRAS developed based on Web 2.0 is user friendly and up to expectations especially for academic staff and the management. However, some users at that time have suggested that the interface of the system could be enhanced.

\subsection{Beyond the pilot phase Implementation}

As mentioned earlier, the implementation of PuTRAS was piloted in UiTM, Sarawak campus. Besides the positive feedback given by the users, the system has also won various awards during its pilot phase implementation in Sarawak campus.

Various awards that have been won by the project are such as Best Management Award in Konvensyen Amalan Pengurusan Terbaik UiTM 2008, Bronze Medal Award in International Invention, Innovation and Technology Exhibition (ITEX) 2008, Gold Medal Award in Invention, Innovation and Design Exhibition (IID) 2008 and Second Prize in Sarawak Federal Secretary's ICT Award 2007. These awards show that PuTRAS is an innovative information system that has effectively met its objectives and has been highly accepted by its users especially the UiTM, Sarawak campus staff.

The confidence gained through the positive feedback and awards won has encouraged the implementation of PuTRAS to be extended to other campuses of UiTM. Implementation of PuTRAS in UiTM, Sabah campus has been completed in February 2009, UiTM, Terengganu campus in June 2009 and UiTM, Johor campus in May 2010.

In addition, the publication module in PuTRAS has been adopted by the Publication Unit of the University (UPENA) of UiTM with minor modification. The module has been further enhanced and developed into a new system named Publication Repository Information System Management (PRISMa). To date, 19045 publication records has been created in PRISMa by 6596 users from all various faculties and branch campuses of UiTM.

\section{CONCLUSIONS}

PuTRAS is a successful example of using Web 2.0 technology to implement an in-house information system to store and analyze staff publication, training and research records. The effectiveness of the system is clearly shown when PuTRAS has significantly helped to reduce the time and cost consumption of the related tasks. Feedback from users and rapid increment of the records in the system also infer that most of the academic staff in UiTM can create content in Web 2.0 environment and are satisfied with the system.

\section{References}

[1] Achour M., Betz, F., Dovgal, A., Lopes, N., Magnusson, H., Richter, G., Abt B., Ahto, J., Aulbach, A., Beckham, D., Bakken, S., Bugüner, N.B., Castagnetto, J.M., Chmara, R., Coates, S., Coggeshall, J., Cortesi, S., Cowburn, P., Egeberg, D., Fischer, M., Furlong, W., Golemon, S., Hirokawa, R., House, B., Joye, P.A., Kneuss, E., Koizumi, M., Lerdorf, R., Lindeman, A., Malyshev, S., Martinez, R., McGuire, R., Nielsen, K.S., Ohgaki, Y., Quadling, R., Rethans, D., Richards, R., Roobol, S., Schmid, E., Schoefbeck, T., Schumann, S., Scott, D., Takagi, M., Torres, Y., Wallner, M., Wilson, L.T., Winstead, J., Wolffelaar, J. \& Zmievski, A., "PHP Manual”,. http:/www.php.net/manual/en/, (Retrieved 06.29.10).

[2] Cifuentes, L., Sharp, A., Bulu, S., Benz, M. \& Stough, LM. (2009). "Developing a Web 2.0-based system with user-authored content for community use and teacher education”, Educational Technology Research and Development, vol. 58(4), pp. 377-398, 2009.

[3] Jones, T.S. \& Ritchey, R.C., "Rapid Prototyping Methodology In Action: A developmental study", Educational Technology Research and Development, vol. 48(2), pp. 63-80. 2000.

[3] Lenhart, A., Horrigan, J. \& Fallows, D., "Content Creation Online. Pew Internet \& American Life Project Research Report", http://www.pewinternet.org/ /media//Files/Reports/2004/PIP_Content_Creation_Report.pdf.pdf, (Retrieved 01.12.11). 
[4] Rainer, K., Turban E. \& Potter, R., Chapter 10: Acquiring IT Application, Introduction to Information System, Supporting and Transforming Business. USA: Wiley. 2007.

[5] Riedling, K. \& Selberherr, S., "A Web-Based Publication Database for Performance Evaluation and Research Documentation", http://publik.tuwien.ac.at/files/PubDat_110259.pdf, (Retrieved 06.12.10).

[6] Shelly, G.B. \& Vermant, M.E., Discovering Computers - Fundamentals (2020 ed.), pp.316. Boston: Course Technology, 2010.

[7] Trémeaux, J.M., "Libchart - Simple PHP chart drawing library", http://naku.dohcrew.com/libchart/pages/introduction, (Retrieved 07.05.10). 